\title{
Relationship Development: A Micro-Foundation for the Internationalization Process of the Multinational Business Enterprise
}

\author{
Jan-Erik Vahlne ${ }^{1} \cdot$ Waheed Akbar Bhatti ${ }^{2}$
}

Received: 9 July 2018 / Revised: 15 October 2018 / Accepted: 3 December 2018 /

Published online: 18 December 2018

(c) The Author(s) 2018

\begin{abstract}
The interplay between knowledge development and commitments is the driving force in the Uppsala internationalization process model. We perform a qualitative thematic analysis of longitudinal data, exploring how relationship knowledge development in supplier-customer relationships leads to commitments through opportunity identification. The results validate our claim that relationship knowledge development as a dynamic capability can influence the focal organization's ability to over time, under changing needs and contexts, harness operational capabilities that lead to at least satisfactory performance. Judging from results, the relationship knowledge development process produces a change in commitments, thereby constituting a critical micro-foundation for the internationalization and evolution process as explained in the Uppsala model.
\end{abstract}

Keywords Uppsala model · Relationship knowledge development process · Dynamic capabilities · Internationalization process

\section{Introduction}

The Uppsala model continues to evolve into a paradigmatic framework applicable to studies of the multinational business enterprise (MBE) (Håkansson and Kappen 2017; Vahlne and Johanson 2013, 2017). There is still scope for improvements and scrutiny of critical assumptions and micro-foundations (Coviello et al. 2017). This article serves the purpose, detailed below, of investigating the

Waheed Akbar Bhatti

wbhatti@uva.fi

1 Centre for International Business Studies, School of Business, Economics and Law, University of Gothenburg, Gothenburg, Sweden

2 The School of Marketing and Communication, University of Vaasa, Vaasa, Finland 
micro-foundation of relationship development, a critical element of the process of MBE internationalization and evolution.

The Uppsala model is located at the micro-level, and the firm as a whole is the unit of analysis. In early versions of the model, the focal firm acted in a faceless market; later, with the introduction of the network view of markets (Håkansson 1982; Johanson and Vahlne 2009 and sources given therein), the model was developed into one of interaction between, formally independent, parties performing exchange in the market: The processes of knowledge development and commitments were and are seen as occurring at both ends of the relationship between, for example, a supplier and a customer. Developments of relationships, development of relationship knowledge and mutual commitments are accordingly critical elements of internationalization.

The latest version of the Uppsala model attempts to widen the performance dimension of the change variables from internationalization to evolution (Vahlne and Johanson 2017). Internationalization is of course seen as a dimension of evolution. The widening has meant that commitments to other strategic behaviors improving on the firm-specific advantages (FSAs) are paid attention to (Dunning and Lundan 2008). Such behaviors include strategy making, technology development, and organizational development, e.g., development of entrepreneurial capabilities. One more such advantage is access to relationships that is membership of relevant networks. Liability of outsidership is consequently a disadvantage (Johanson and Vahlne 2009). To enjoy an advantage, by exploiting an operating capability, the capability/advantage has to be built. This happens via dynamic capabilities possessed by the focal firm (Teece et al. 1997). The Uppsala model, focusing on change processes constituting internationalization, was consequently enriched by the inclusion of the dynamic capabilities perspective. Operating and dynamic capabilities are integrated into the model (cf. Fig. 1) (Vahlne and Johanson 2013, 2017).

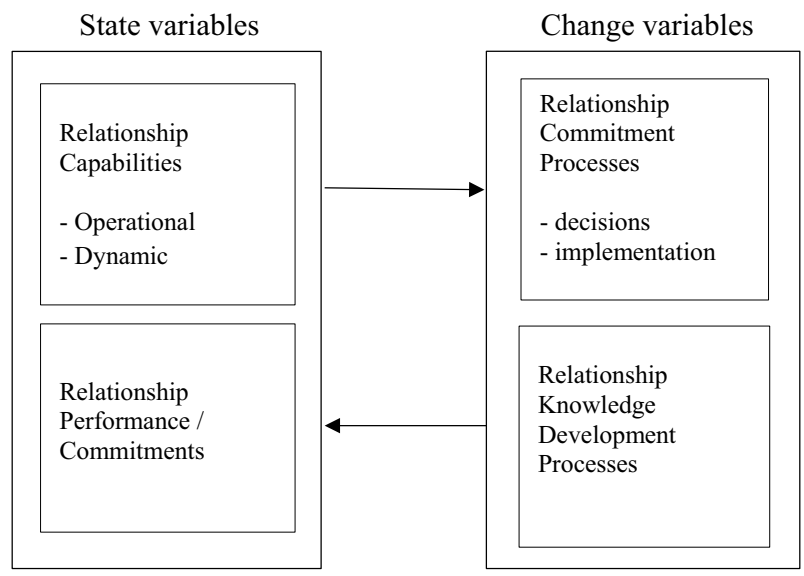

Fig. 1 The relationship development model [The study uses the model as an adjusted version of the Uppsala Model 2017 (Vahlne and Johanson 2017)] 
Dynamic capabilities research has tended to concentrate on the product- and technology-related aspects. However, product-focused organizations, which have conventionally focused their competitiveness on product qualities and patents, are progressively shifting their attention toward solution offering (Kindström et al. 2013). Still, there are no empirical studies of the dynamic capability of developing relationships, knowledge development (Aykol and Leonidou 2018; Eriksson 2014; Jonsson 2007). Hence, the research question for this paper is to shed light on the relationship development micro-foundation of the Uppsala model. As has been shown above, this micro-foundation has been only assumed to exist, but not explicitly studied empirically. Hence, if we can show the importance of this micro-foundation empirically, we have indeed moved the research field forward as relationship building and development is at the heart of the internationalization process. To conclude, the contribution of this paper is that, in one important aspect, so far missing, the Uppsala model rests on solid ground. Now, our study includes only two case studies, and regardless of the nature of our findings, empirical studies have to be continued.

Against the background of the research question and attempted contribution, our objective is to empirically study relationship building processes and the subsequent change of commitments between the two parties of a supplier-customer relationship. Consistent with the process ontology on which the Uppsala model is based, the approach is to perform, longitudinal, detailed case studies of relationship development.

The paper continues with a summary of the theoretical background, outlining the essential building blocks: the Uppsala model, the capabilities approach, relationship knowledge development and a final section on relevant differences between large and small companies. A section on methodology is followed by a description and analysis of the empirical findings. Concluding remarks and ideas for future research finalize the paper.

\section{Theoretical Background}

In this section, we will focus on three phenomena, namely the evolutionary process of the MBE, dynamic capabilities and relationship knowledge development, which we try to interconnect in this work. This serves the purpose of providing the theoretical base for our empirical study.

\subsection{The Uppsala Model}

The earlier version of the Uppsala model explained the internationalization process as an interplay between the processes of knowledge development and commitments (Johanson and Vahlne 1977, 2009). The latest version still relies upon those mechanisms, but the phenomenon explained is the evolutionary process of the MBE. The intention is to focus not only on the internationalization process but also on the development of the firm-specific advantages (FSAs), such as processes of developing new technology or strategic change (Vahlne and Johanson 2017). However, these 
processes are cumulative, and causal relationships are seen as relationships between state and change variables (Fig. 1). Knowledge development affects the status of the capabilities, which in turn impacts on ongoing knowledge development and commitments. A commitment decision, such as an investment in a local organization of the focal firm, will, of course, change the degree of commitment and performance, but most probably also the need for knowledge development. The supplier relationship development model as depicted in Fig. 1 is a version of the Uppsala model 2017 adjusted to fit the paper's objective of applying the process view to the development of individual relationships that is the relationship between the focal firm as a supplier and an individual customer. Typically such a relationship is handled by particular departments at the respective companies and some designated individuals.

As follows from Fig. 1, we see the Uppsala model as being completely applicable at the level of the evolution of the individual relationship. The operational capability of the relationship (upper left-hand box of the figure) is the ability to serve the customer in an at least satisfactory manner. The dynamic capability is the ability to change the operational capability, for example by adjusting the product or services offered. The commitment decisions (upper right-hand box) may, for example, concern investments to adjust the product to the changing needs of the customer. An implementation may take the shape of a trial and error process in developing a new version of the product. The performance dimension (lower left-hand box) can be profitability and sales growth, while commitments could formally and/or informally state that the customer will be serviced when needed, even at a high cost. Relationship knowledge development (lower right-hand box) includes learning about the customer's needs, building a trusting relationship and, often in cooperation with the customer, creating a better product and service offering. Increased commitments constitute internationalization.

Relationship development is characterized by uncertainty, as the focal firm has to cope with contexts characterized by many unknowns, often implying that the process proceeds incrementally in line with the interplay between knowledge development and commitments, with the firm deciding to proceed if what it learns is promising for the future (Johanson and Vahlne 1977, 2006, 2009). Johanson and Vahlne (2003) conclude that an organization's international expansion is initially the result of developing its existing relationships. However, existing relationships may serve to open up new such relationships through the dissemination of knowledge of opportunities.

The driving force in the internationalization process is the organizations' experiential knowledge of opportunities (Johanson and Vahlne 1977) acquired from market operations and inter-organizational relationships, e.g., relationships with customers. Creative efforts lead to continuous learning from network parties and increased resource commitments in the international marketplace (Johnson et al. 2009). Opportunities must concern not only the potential concerning the focal relationship but also similar relationships in the same or new markets. The network by its nature serves as an extended knowledge base: knowledge of other relevant parties may be transmitted via the focal customer (Johanson and Vahlne 2009). Moreover, it should be mentioned that such privileged knowledge is by no means public, but is instead confined to the parties involved. The knowledge development process as 
Johanson and Vahlne (2006) posit, is subject to interrelated mechanisms about and commitment to identified opportunity. Identified opportunity exploitation carries the incremental internationalization process through relationship interaction (Johanson and Vahlne 2006).

Organizations learn and gain experience through relationship knowledge development. The network is a broader web of connected relationships operating as a knowledge sharing system. The inter-organizational relationships provide the participating organizations with an opportunity to learn and share from the knowledge hub (Evers and Knight 2008) or act as gatekeepers (Guercini and Runfola 2010) or as channels of information flow (Cano-Kollmann et al. 2016). Knowledge is gained not only through organizational relationships (Guercini and Runfola 2010) but also through social relationships between individuals (Loane and Bell 2006). This knowledge is experience-based and learned through physical interaction. Experiential learning from inter-organizational relationships provides a platform to study, compare and analyze the market situation and take advantage of identified opportunities (Eriksson et al. 2000). Experiential learning has a positive influence on the organizational capability to internationalize in foreign markets (Shane 2000). Relationship knowledge development can affect its competitive market positioning through knowledge acquisition from external networks. Naturally, we stress the importance of experiential learning. However, as pointed out by for example Forsgren (2002), other ways of learning such as active search, grafting and imitation can be of importance.

To conclude, knowledge makes it possible to identify and/or develop opportunities not only promotes entrepreneurship but allows the focal firm to enter new markets and networks (Mainela et al. 2014; Santangelo and Meyer 2017). As firms are acting on opportunities, the micro-foundation of relationship learning is critical to the explanation of internationalization as explained by the Uppsala model. Still, this micro-foundation has not been researched (Coviello et al. 2017). Hence, the objective of this paper: How can opportunities be identified, possibly evolve, in an ongoing relationship.

The knowledge needed by the internationalizing firm can be seen as a typology within three groups of knowledge: internationalization knowledge, institutional knowledge and business knowledge (Eriksson et al. 1997). Internationalization knowledge concerns how to manage the process, and can be seen as encompassing the other two types. Institutional knowledge covers the norms and regulations prevailing in the foreign market, and business knowledge involves awareness of customer needs, competitors and ways of doing business in the foreign market. We see those types of knowledge as comprising an input into the dynamic capability of entering and sustainably engaging in business in the foreign market(s). Hence, in our view the knowledge that is collected in one way or another constitutes a resource, together with other resources, mainly managerial capacity, making up those dynamic capabilities. On an operational level, the degree of commitment is visible from the type and magnitude of operations performed in the foreign market. Relying upon an intermediary indicates that the commitment is small. Switching to a more committed mode may involve establishing a subsidiary organization in the market, for example. Performance may be operationalized as the volume of sales or profitability from local operations. 


\subsection{Dynamic Capabilities}

Grounded in the notion that a unique combination of resources provides the basis for competitive advantage, the dynamic capabilities perspective looks at the sustainable competitive advantage as the organizational ability to create, extend and change valuable capabilities and resources over time (Helfat et al. 2007). The dynamic capabilities can be conceptualized from two viewpoints: evolutionary and technical fitness (Teece 2007). Evolutionary fitness is the ability of organizational capabilities to create value, flourish in the market and align with environmental change. Technical fitness signifies the ability of organizational capabilities to ensure that the assigned job is carried out effectively (Helfat et al. 2007). Teece (2014) dynamic capability framework provides an entrepreneurial perspective that stresses the influence of key business processes inside the firm and linking it to its external network. The framework focuses on how firms may create, integrate and deploy their resources, while in parallel managing threats and accomplishing the required transformation. This is because, application of the dynamic capabilities have to lead to the focal firm possessing operating capabilities, corresponding to the activities of the value chain, achieving at least a satisfactory performance.

We stick to the terminology of the Uppsala model: Knowledge development corresponds to sensing and reconfiguration covers both seizing and reconfiguration as explicated by Teece (2007). Knowledge development refers to the acquisition of applicable customer intelligence, critical for adjusting product and marketing means (Day 2004; Teece 2007). Likewise, customer knowledge acquisition is the crucial basis for service development (Edvardsson et al. 2006). To enable an organization to acquire superior operational capabilities, it is not enough to merely invest in technology-related assets. The focal firm must have a business model that is capable of exploiting and sustaining newly identified opportunities (Chesbrough 2010; Teece 2010). An adjustment of the current behavior vis-ávis a particular customer, may be sufficient to sustain the exploitation of a new opportunity; however, when the environment changes, management will have to embark on another cycle of reconfiguration (Helfat et al. 2007).

\subsection{Relationship Knowledge Development}

In the Uppsala model, the knowledge development process is the aggregate of three sub-processes: learning, creating and trust-building (Vahlne and Johanson 2017). Learning is seen as the acquisition of new knowledge, and creating is the application of the new knowledge, often in combination with existing knowledge. Trust-building, both internally and externally, is a prerequisite for both knowledge sharing and creation. Also, knowledge is not neutral: The quality of the source is critical to the credibility of the knowledge. Of course, the focal firm entering a new foreign market needs to develop relationships with many different sorts of partners. For instance, the company might have to contact a supplier for 
an input that must be produced locally. However, for the sake of simplicity, in this project, we focus on the most important partners: the customers, both potential and actual.

Such relationships usually include several managers who deal with various dimensions of the focal relationship. Together those involved from the two parties over time build trust and create routines through joint coordination (Cunningham and Homse 1986). There is a certain probability that these processes of learning, trust-building, and creation will lead to higher degrees of commitment (Andersson and Weitz 1992). As shown by Morgan and Hunt (1994), trust-building is vital for commitment. These processes take time, not rarely up to five years (Hohenthal 2001). Hence, relationship building is an investment (Dyer and Singh 1998).

As Drucker (1999, p. 87) advises, "only by asking the customer, by watching him, by trying to understand his behavior can one find out who he is, what he does, how he buys, how he uses what he buys, what he expects, what he values and so on". Vahlne and Johanson (2013, p. 195) interpret developing opportunities in relationship interaction as two tangled subprocesses in internationalization: "Learning, mainly experiential learning and commitment building". None of these concern country borders, but existing and potential relationships. Knowledge development is a continuous process that takes place at both ends of the relationship.

Selnes and Sallis (2003) explain that the concept of relationship learning provides a means of measuring the learning taking place in a relationship. More significantly, relationship-level learning measures the shared change between knowledge sharing, its common sense-making, and integration of knowledge into the relationship-specific knowledge base. Knowledge sharing within a relationship increases the supplier understanding of the customer needs during the interaction process (Nonaka and Takeuchi 1995). Frequently, a supplier has insufficient knowledge of its customer's needs; on the other hand, the customer has insufficient knowledge of the supplier's resources and capabilities (Kohtamäki et al. 2013).

Research (Håkansson and Johanson 2001; Pahlberg 2001) identifies three types of learning in a supplier-customer relationship. Firstly, the parties learn organizational ways of working that help understands the organization and hence contribute to strengthening the relationship. Secondly, interactions enable the parties to learn new skills and nurture competence that can be utilized within or in other organizational relationships. Thirdly, the parties learn how to coordinate activities with other relationships. Chen (2000) concludes said that organizations could build their relationship networks and connect them based on these three types of learning. Jarvis (2009) says that the individual who learns is the outcome of that learning and that this changed individual may cause numerous different social outcomes.

\section{Methodology}

This study is interested in developing our understanding of relationship knowledge development as a dynamic organizational capability that is a process that develops over time. The inter-organizational relationship interactions identify customer needs leading to recognition and exploitation of identified opportunities for 
internationalization, which by definition is a phenomenon that evolves. We theoretically rely upon the Uppsala model and empirically employ longitudinal case studies, as the application of the Uppsala model in longitudinal cases was successful in the past and a recent study (Vahlne et al. 2011).

We see our project as pioneering in the sense that there are no empirical studies on the micro-foundations of the Uppsala model. We hope that the results can be exploited in hypothesis formulation. Our sample is hence of a convenience nature as access was guiding the choice of case companies.

Yin (2003) says case study is influenced by a qualitative method in search for meaning instead of truth. Yin identified three situations wherein case study is a preferred methodology: To analytically test a theory and its application on the case firm, to contrast and compare a particular situation in a case and/or when a researcher wants to learn new from a slightly less studied perspective. In addition to that, Ghauri (2004, p. 109) identifies case studies as, "both the process of learning about the case and the product of learning". Langley (2009, p. 413) suggests that process research can study, "phenomenon by tracing it backward into the past (retrospective studies), by following it forward into the future (longitudinal case studies), by examining how it is constituted". An advantage of mining the past is that the conclusion is identifiable and the researcher knows what the process model will explain. This requires precise data collection by focusing on those features directly connected to the outcome. As the outcome is the essential motive for the study. In our work the data collection is perspective. However, the analysis is retrospective which constitutes a limitation. Miles and Huberman (1994) recommend interweaving data collection and analysis from the first interview. Case studies are integrated, allowing examination of the phenomenon from different viewpoints, crossing boundaries among various factors and covering a period (Ghauri 2004).

The objective of this study is to collect material from the two case relationships, building a longitudinal narrative, focusing on the concepts included in the model. The data collection did not take the shape of formal interviews, but was more of a conversation during which the interviewee told a story and was prompted by followup questions such as 'Why?', 'Who did what?', 'When?' and so on. Consequently, exact measures of the theoretical constructs were not needed, as after visiting the case supplier companies the interviewer interpreted the story in the terminology indicated by the theoretical model. In this way, we managed to 'catch' stories about how supplier relationships evolved: Knowledge developed on the needs and characteristics of the customer could change the ability to serve the customer and the level of commitment to the focal relationship, in turn potentially affecting commitments to the relationship and accordingly the performance. This, of course, did not happen in isolation but was paralleled by a similar process on the customer side, which we did not learn about. We believe that this empirical approach functioned well for our exploratory study on internationalization at the level of the individual relationship.

This study uses an explorative approach to ascertain how suppliers learn to understand customers' needs and address them through the value creation process in their offering (Lehrer et al. 2012; Tuli et al. 2007). The multinational enterprise case firm is a leading European lifecycle power solutions provider for the selected energy markets and global marine markets. Their emphasis on R\&D enables them to be 
at the forefront of innovation and technology in the energy industry. They strive to offer solutions to the customer through better technologies that benefit not only the customers but the environment as well. The small and medium enterprise case firm is also Europe based manufacturer of electric drivetrain technology for industrial and renewable applications. They are power-generating ingredients provider adding value by cost reduction through collaboration and networking for new energy for the market. Hence influencing a profitable generation of power in addition to process optimization and energy usage.

Our purposeful sampling approach sought to recruit managers with significant customer interaction experience (Töllner et al. 2011; Tuli et al. 2007), accessing numerous professional network platforms as well as personal contacts. Because of this approach, access and trustful relationship between interviewees and interviewer guided the choices of case companies: one large, internally experienced (MBE) and one, smaller, the internationally inexperienced company (SME). This research focuses on managers who can contribute to the research by sharing their experiential learning. The study respondents are middle and senior managers with minimum industry experience of five years, but in my study sample, average experience is 10-20 years. These individuals are the key contacts for direct communication in inter-firm relationships, and they are knowledgeable about the customer and own offerings (Tuli et al. 2007). The interviewed managers are at different levels and hence can provide a broad view of acquired learning and knowledge sharing experience. We conducted 14 in-depth interviews with managers (Table 1) from both the MBE and SME case firms operating in the energy industry during the year 2016 in the initial phase and a couple of follow-up interviews in summer 2017.

The interviewees have significant experience in the development and sale of solutions. The study focused on individuals who regularly interact with the organizations' external network and hence can contribute to the research. To protect the participating firms' interests, as well as to maintain ethical integrity names are anonymized in the quotes (Kirkup and Carrigan 2000). We interviewed middle and senior managers. The individuals are at different stages of their careers, with different levels of experience and job responsibilities. The study participants answer the same questions focusing on the background of the individual, present responsibilities in the organization, and knowledge sharing experience in their interactions with customers or suppliers. The

Table 1 Case respondent description

\begin{tabular}{llll}
\hline Case firm & MBE & SME \\
Established since & $50+$ years & \multicolumn{1}{c}{ 12 years } & 2016 \\
Interviews conducted & 2016 & 3 & 2017 \\
& 2017 & \\
Length of interview & $52-112$ min (average 76 min) & $2+2$ \\
Senior + middle manager & $2+2$ & 8 to 20+ years \\
Industry experience & 10 to 20+ years & $6+$ to 12+ years \\
With the firm & $8+$ to 20+ years & 5 years (minimum) \\
Customer interaction & 5 years (minimum) & \\
\hline
\end{tabular}


questions are shared via email ahead of the interview date to enable them to provide healthy feedback and quote relevant examples.

As emphasized by Dyer and Wilkins (1991, p. 617), "if executed well, case studies are powerful [when] authors have described general phenomenon so well that others have little difficulty seeing the same phenomenon in their own experience and research". The data collection is through episodic interviews (Flick 2014). Episodic interviews are based on an interview schedule and usually address two different types of knowledge. Episodic knowledge is organized closer to experiences and linked to concrete situations and circumstances. Semantic knowledge is based on concepts, assumptions, and relations that are abstracted and generalized from these. For the former, the course of the situation within its context is the primary unit around which knowledge is organized. In the latter, concepts and their relations to each other are the central units.

An episodic interview yields context-related presentations in the form of a narrative because these are closer to experiences and their generative context than other presentational forms. The respondents share episodic knowledge when asked to recount subjectively relative situations in their everyday professional lives to illustrate answers to the more general questions that were asked earlier (e.g., situations in which specific knowledge is sharing by a network member led to your learning and new knowledge acquisition). As Dyer and Wilkins (1991, p. 615) argue, the ultimate objective of a case study research is to provide "a rich description of the social scene, to describe the context in which events occur". An episodic interview is not an attempt to artificially stylize experiences as a complete narrative. Instead, it starts with episodic-situational forms of experiential knowledge (Flick 2014). The interview pays particular attention to the episodes or events in which the participant has had experiences that seem to be relevant to the question of the study.

\section{Empirical Findings}

In this section, we present the empirical results from the two cases, the MBE and the SME and discuss the results. When addressing how a change took place, Van de Ven and Huber (1990) say first a story is required that narrates the pattern of events. Once this sequence of events (the knowledge development process) is found, the researcher can return to questions concerning the causes of those events in the process pattern. To understand how the change took place, Abbott (1988) advises altering the typical analysis method. He recommends instead of variables, first generalizing the story or history. This method helps preserve sequence and order of events in presenting theoretical generalizations about the change process.

\subsection{Study Cases}

\subsubsection{The MBE}

The MBE case company is a global energy solutions provider. Over a decade ago, preferences in the energy market began to change. Renewable green values became 
stronger than fossil fuels, and one could see wind and solar power picking up strong momentum. Everything related to fossil fuels is considered unhealthy, and lobbyists want to phase them out. However, our case company business is in the fossil fuels market. So, the question for the case company arises, what should it do in this changing scenario? Close the business and go home or do something else to survive? The company decided to hold workshops about how it will develop and how the industry business will develop over time in response to new preferences. They started brainstorming about everything, from one extreme to another. That was an interesting exercise. The outcome was that, yes, the world is moving towards a greener society, but through this shift, the case company identified more growth opportunities than if it would operate only in the fossil fuel market. The MBE recognized that its flexible power plants could provide a perfect complement to green energy and assist in creating more green projects. That was an eye-opener that enabled the company to believe in the future again. That said, the MBE realized that it would have to update its products to address new market segment needs. The company then looked at what sort of value it can bring to the market and how it should satisfy customer needs.

The MBE learned from the changing market preferences and identified a new market segment for itself. However, no one can be sure what tomorrow will bring regarding demand, and renewable projects require a significant investment, so only financially stable companies can compete. When the MBE identified a new segment opportunity, it explored what sort of value it can bring to the table. What value does the customer gain from buying a power plant from the MBE instead of opting for an alternative solution? The problem with renewables is that when a large array of solar panels is in operation and clouds come sailing over it, electricity production is shut down in a matter of seconds. The solar plant thus needs a backup solution to ensure uninterrupted energy supply - a fast-reacting power station. Standard conventional power plants are not fast reacting, whereas our case company has engine-based power plants that are fast reacting. This created a new market segment for the MBE.

The case company has dropped the salesperson approach and now treats its customers as partners or acts as their consultants. Its philosophy is that a salesperson should be a partner and a colleague to the customer. Hence, for practical reasons, it is important to be close to customers. Face-to-face interactions build connections and develop trust in the relationship. Sometimes the customer does not know that he or she is a customer, so the MBE and customer should identify opportunities and develop the project together. This process includes sensing an opportunity in the market and discussing the idea with the client to determine how they can jointly capitalize on it. The internalizing of acquired knowledge takes time. If the MBE sees that a customer is sitting on an opportunity but has not realized this, then its business development team approaches the customer with a proposition: "Hey, listen, we have a proposal we wish to discuss, an excellent opportunity that we could co-develop."

One of the clients of the MBE is a city municipality in the USA. The city has been moving towards a green approach with a low emissions power system, seeking to produce over two-thirds of its energy needs with renewables before the end of this decade. The city planned to achieve this goal through solar and wind 
technologies. However, since these renewable energy supply solutions are prone to fluctuations, the MBE's internal combustion engine technology provided perfect backup support to ensure uninterrupted power supply. The business development team approached the city municipality and discussed how they could join forces to achieve the renewable conversion target. The team explained that flexible power generation ensures uninterrupted power supply from renewable units. Flexible power generation provides an excellent match with renewables. When wind and solar energy is not being produced, these flexible units come into play, ensuring continuous energy supply. The plant has a quick start and stop ability that provides an excellent alternative to gas turbines. Not only that, it delivers power generation with low emissions, which is highly valued by the end user, consumer of the city's energy. This solution offered by the MBE is expected to reduce emissions by approximately $78 \%$, delivering reliable and affordable electricity and helping the city save millions of dollars in energy production costs. The plant will go into commercial operation by mid-2018. This is just another example of how the MBE's knowledge development process helps its systematic market development strategy in successful internationalization.

Change is not an easy task, as it requires internalizing new knowledge, sensemaking about how the business segment is developing and then advocating these things. Internal training and many workshops are required to demonstrate the viability of these cases. The training and workshops are part of an internal process first to change the mindset of the management and employees and then introduce it into the outer world to actualize change management in the business. This change is a long process that started with internal training and workshops with the global sales team and took about two years to mobilize internally. Of course, in parallel, the company also tried to advocate it externally to its existing and potential customers. The process to develop a power plant business from the first idea to getting the financing and from finalizing the deals to construction takes about four to five years.

The MBE has been quite aggressive in its business development approach. It has a robust knowledge development process in place that allows it to react to changing customer needs over time swiftly. Experiential learning from internationalization lessons gained from one relationship can be put to use in another relationship in the same market or a new market. There is a strong emphasis on workshops and training to stay up to date with market developments. The company put in place an explore and exploit activity and hence reconfigured the coordination systems essential for decision-making in the internationalization process. Trust-building in the relationship identifies growth opportunities leading to new commitments. This capability allowed the company to offer customized solutions to its clients-industry, utilities, and independent power providers-in Bangladesh, India, and Pakistan. Presently in China, the MBE is providing renewable solutions, as the Chinese market is aggressively moving towards renewable energy. This growth strategy has yielded fruitful results - the company has successfully expanded in the Asian, African and North American markets. Thus, in this case, the change in approach led to the opening of new and innovative routes for future expansion. 


\subsubsection{The SME}

The supplier case company is a technology-based niche SME in the renewable energy products business. The company started with a management team who had diverse experience in energy and technology. The SME management had been in the industry long enough to know who's who in the value chain. Its top managers started contacting their past colleagues, shared their ideas with them, and asked if they were interested in working together. By doing so, they put an idea (new knowledge) into a melting pot, exploring and utilizing it in a new way. If their contacts are not interested, they can forward them to someone else who may be interested, and then management contacts them with their reference. By reaching out, they build a web of value chain relationships.

The supplier company's management believes in a face-to-face discussion with customers. Their approach is to operate in foreign markets through locals instead of expats. The management plan regular trips to different international markets and set up meetings with existing customers, suppliers and also with potential customers and suppliers through local board members. The case company's management takes the local management with them to meet the clients. These interactions help in understanding customer needs and what the customers do not have. The managers go out into the field, approach the customers and tell them about a solution that the customer has not been using, asking if they would like to switch to it. For example, as the specific product model is already operational in the European market, it is easier for new customers to appreciate it and evaluate its performance to consider switching to it. This active opportunity identification approach is getting a fruitful response.

The case company follows an aggressive business model. It works with one of the largest wind turbine manufacturers in China and supplied it with a wind power generator. The product ran into some technical problems in a specific turbine project. The company received a call from the client about the issue and had problems resolving it. The client sounded upset and unhappy. Once the case company's top management heard about this and realized the gravity of the situation, they immediately decided to fly out along with the technical staff to see "what was wrong with it." They flew out the next day and arrived at the site. The Chinese were surprised to see the top management, including the chief customer officer, deputy managing director, and VP marketing with the technical team at the site. The Chinese customer was impressed that the supplier company's top management had the guts to show up with the technical team at a point when the customer was shouting at them. The customer was overwhelmed, as this showed them that the case company cared for its customers, and in the customer's opinion most companies will never send top management in such a situation. Discussion and sharing turned what seemed like a big problem into a success for the case company. One operational change the SME did after this experience was to train its customers to service the product themselves, instead of sending teams to service on a regular basis.

The problem was resolved, and the site staff was briefed about why this had taken place. This incident added to the list of things the supplier company had performed that demonstrate that it cares and actively responds to customer problems or needs. This 
customer management approach has changed the nature of their relationship, as the customer respects how the supplier owns the product and management showed guts by showing up in person instead of just sending a technical team. Thanks to these interactions, the supplier-customer relationship changed to a partnership at the Chinese firm's invitation. The SME was happily surprised by the offer and accepted it in no time. The supplier company says that the big Chinese firm does not need it to be a partner, but made the offer because of the company's approach to addressing customer issues and concerns. The Chinese firm gives the SME part of the volume thanks to the attitude and cares it has demonstrated towards customers. The supplier company's reputation for caring for its customers has spread in the market and has led to an expansion in its network of relationships. The realization of closeness and being receptive to customers is vital in relationship development, as it lays the foundation for the long term. The SME's management decided to train the customers in product servicing, instead of sending out technical teams to provide service on a regular basis. This change showed trust in the customer as well as a commitment to the relationship. Experiential relationship learning led management to implement a customer relationship strategy focusing on effectiveness and patience with change, resulting in trust development and commitment to relationship building.

Close relationships enable faster awareness of changing market preferences and customer needs. A customer focus helps in relationship strengthening, which facilitates error correction, problem resolution, and opportunity identification. The MBE case firm learned from the change in market preferences and adapted its products to address new market segment needs. The communication and the interactional ability of the SME enabled it to evolve into a partnership with the customer. The driving factors are alertness, understanding of the needs and ability to react quickly. By showing concern for the needs of the customer through its actions, the SME case firm earned the customer's respect and strengthened not only its existing relationship but also other relationships in the Asia Pacific market. Trust-building in a relationship is a priority that opens doors to opportunities and commitment in the long term.

\section{Analysis}

In this section, we analyze the case events in the terminology of the model (Fig. 1), starting with the change aspects. Knowledge development processes consist of three subprocesses: learning, creating and trust-building. As these sub-processes are intertwined, they are to some extent dealt with in parallel, even if there are chapter sections for each sub-process. The commitment processes include decisions and implementation, discussed in the same section. We then turn to the capabilities of the firm, operational and dynamic. Finally, we pay attention to performance and commitments made evident.

\subsection{Relationship Learning}

We see a broader role for relationship learning as a conduit for knowledge flow irrespective of distance. Interaction in the relationship is about learning, but 
new opportunities emerge from the process. A manager at the MBE highlights that openness and sharing "depend on the customer and the level of the relationship." As the manager explained, a trusting relationship encourages the free flow of knowledge; once this trust is in place, the nature of the relationship changes from a formal to an informal sharing relationship. The goodwill of a trustworthy organization spreads in the market and stimulates other relationship development within the same or new markets. This is a critical strength to have when entering or expanding in an existing market.

The SME director says that you must "evaluate what your competitor is doing, both in daily business and [regarding] what you see them test and play around with [...] in the market. Look at the competition, get some cues from the competition." The root of the knowledge development process is attentive communication, which nurtures the relationship. Interactional social exchange uncovers customers' operations and the usage of the organizational offering. Furthermore, the customers raise issues and share input on offering improvement. However, the level of sharing is dependent upon mutual trust among the relationship partners. The customers share information about needs, trends, competitor offerings and institutional changes, all of which present opportunities. Awareness of customer offering utilization provides learning about their needs (existing and upcoming). Hence, relationship learning yields knowledge about the customer's operations and market. This enables the acquisition of knowledge that can be translated into value. This organizational capability can be utilized in all organizational relationships. The visible learning difference between the MBE and SME is the ability to be attentive to the customer and successfully interpret what is being said and not said, and this develops with experience. In the case of the SME, its role may be that of a supplier of parts rather than end-to-end products or services, which limit the relationship_-its responsibilities are limited to specifications and timely delivery.

The traditional role of the salesperson has evolved into a business development manager, says the MBE director: "So that he should not go and say buy something; I will give a discount. He should be a consultant to the customer, and identify opportunities and try together to develop the project." In parallel to the above, research has established that intra-firm sharing is a stronger contributor to performance outcomes than inter-firm sharing. Knowledge transfer in intra-organizational relationships tends to make a more substantial contribution than inter-organizational transfer. However, our results expand on this and show that inter-organizational relationship learning lays the foundation for the knowledge development process, through which effective evaluation and sense-making creates new knowledge for potential exploitation in the future. Once experienced, this learning can easily be replicated across relationships, thereby helping the organization in relationship network expansion. Thus we believe that sharing with firm departments is relevant, more exploitable and able to generate the required results.

The sales manager of the SME explains his approach to interaction with clients: "Be receptive to the information, make sure you involve all the levels that can do something about it and take action. It does not help to have mid-level people with no authority seeing the results if they do not have budget authority." The documentation 
and sharing of information acquired from the meeting with the customer take place internally as a routine procedure. The method and means of sharing vary across organizations, but all companies hold internal meetings to deliberate on the acquired learning. MBEs focus more on data analytics, evaluate the customer and firm offering behavior, identify profitable and not so profitable relationships, and highlight patterns and trends in them. Data analytics assist in determining how well the firm is meeting those needs and facilitate the orchestration of a development plan to address identified customer needs. Evaluation allows for sense-making of how the customer needs and purchase trends have progressed, as well as the profitability of particular relationships. Data analytics assist in determining how well the firm is meeting those needs. The review process will help orchestrate an offering development plan to address identified customer needs. SMEs provide parts or smaller products, and hence the adjustments and revisions are more accessible and less time-consuming than at MBEs.

\subsection{Creating Within the Relationship}

There are many examples in the cases where it is evident that knowledge development is far from equal to 'passive' internalization of information and knowledge. More or less simultaneously to learning, new knowledge is created. This is evident from the effort to change the relationship from one of vendor-customer to a partnership where the two parties together try to solve upcoming problems. This sort of relationship presupposes a sense of trust which takes a long time to establish. It is also evident from the cases that even if experiential learning is important, also active search is on and off necessary. This, the Uppsala model has to incorporate (Forsgren 2002). It has been shown, that it is to a large degree in the relationship between supplier and customer that product development happens (Håkansson 1989). This result leads directly to the section on trust-building.

\subsection{Relationship Trust-Building}

Interactional exchange plays an important role in building trust in a relationship, as noted by the general manager of the MBE: "So trust and responsibility or trust and relationships are vital [for] in sharing of knowledge." The evolving environment has changed the traditional roles; now, the director of the MBE says, "I do not think the sharing part is so difficult for us because we communicate quite well internally." From a boundary-spanning perspective in a customer-supplier relationship, trust in the individuals involved in inter-organizational interaction increases trust in their representative organization. This growing trust in a relationship takes an emotional shape; for example, a company might ask itself if it can trust this supplier? This leads to the formation of relationships, which we believe are critical in the internationalization process. The study respondents are unanimous in their view that they must focus on essential information on customer needs and experience of offerings.

It is evident from the cases that trust-building is a critical ingredient, a necessary prerequisite for sharing knowledge and allowing for an attitude of joint efforts: the 
essence of creation. It is of less importance which of the parties who benefits from the outcome of the creative efforts than the improvement itself. The outcome of the relationship building is that the focal company can benefit from the network advantage (Johanson and Vahlne 2009). The obvious example from the cases is that the successful outcome is spread around to customer industry colleagues allowing the focal firm to apply a replication strategy (Winter and Szulanski 2001).

What we have observed may be part of a larger trend. Especially service companies seem to switch from a 'transactional' mode of relating to customers into a 'relational' mode (Coviello et al. 2002). It is no longer a matter of shortsightedly selling but more a matter building a relationship, a long-term partnership. It is really a matter of switching from one business model into another, making sure the hardware functions according to specifications.

\subsection{Relationship Commitment Processes}

Apart from the brain-storming sessions of the MBE, it seems to us that the commitment processes of the MBE and the SME are remarkably similar. Both firms engage personnel at different levels in both decision-making and implementation. In that sense it seems to us that these two firms are 'modern' in the sense that strategic change cannot be successfully accomplished, is not middle-management and other critical employees engaged (Spender 1996). We can talk about multiple change processes as managers at different levels partly in parallel, later converging, leads to change (Hart and Banbury 1994). This view fits well with the ambition of the later version of the Uppsala model, explaining the evolution of the MBE (Vahlne and Johanson 2017) and of course with the view that internationalization, in any case, is to be regarded as a strategic change (Melin 1992).

\subsection{Relationship Operational Capabilities}

The operational capabilities are organizational routines employed to manufacture and interact in relationships. They are the core of organizational experiential learning enabling knowledge creation. This knowledge can be advantageous if opportunities are identified. The MBE case organization approach of serving as a consultant to customers or as their partner has helped unfold multiple opportunities that can be potentially exploited through its business model. The MBE addresses the identified customer needs through collaborative solution provision. On the other hand, the SME case company's firm decision to train customer staff to service the product represents exceptional confidence in a relationship and towards building a long-term market presence. This is an essential characteristic to empower their customer, a practice not normally utilized.

It follows from the case descriptions that the operational capabilities are changed: from selling equipment into partnering, making sure the equipment delivered functions. The attitude of the 'front employees' has to change. It seems that transition is successful as the performance of the case firms seems to improve. 


\subsection{Relationship Dynamic Capabilities}

Relationship knowledge development is the overriding input into dynamic capability in our work, implying that the internationalization process is strongly influenced by relationship learning, knowledge creation, and trust building. The integration and sense-making of acquired knowledge over time lead to internationalization through the interplay of opportunity exploration and exploitation. The MBE has a rigorous training and workshop plan in place to continuously nurture capabilities. This knowledge development process helps in opportunity identification from acquired learning. The business model addresses the identified opportunity through commitments aligning the company's offering of energy solutions across the globe. The SME's ability to offer solutions on a consistent basis hinges on the development of flexible internal mechanisms. Experiential learning nurtures the sense-making capability to explore and exploit growth opportunities as well as help reduce foreign market uncertainty through local presence. The cases are good examples of the application of dynamic capabilities. To begin with, the business model is changed after the performance of the 'brain-storming sessions' providing the focal MBE with an understanding of the changed environment making the previous business model obsolete. Also, the switch from the old type of relationship, supplier-customer, into one of a partnership between, parties jointly benefitting efforts to improve on the product and service offerings is changed. We do not know, but it seems probable that the dynamic capability ultimately rests with top management (Teece 2012). This seems to hold true in both case firms.

\subsection{Relationship Performance/Commitments}

To stay competitive, firms are investing in $R \& D$ and encouraging innovative thinking, as noted by the director of the MBE: "Process management involves evaluations and feedback, questioning and answering. Moreover, you can give people a goal to drive innovation [...] [they] can tap customer feedback and test and experiment with things that address customers' needs in the way. You can give them bonuses and incentives to do that and if you do not do that they are not awarded for not taking any chances." The MBE's sense-making out of acquired knowledge leads to strategizing on exploiting new market opportunities. The shift towards a greener market provides growth potential for the MBE: By altering/updating its products to suit the segment needs, it can successfully create a new market segment solution. The performance from the developed relationship is obviously positive.

The dynamic market environment and technological advancements are changing the way business is managed. This change includes a commitment towards the customer and his business which requires the employees to be willing and skilled with tools and techniques to serve the customer. Also, effective sense-making of market change and the required adaptation is key in maintaining a competitive organizational edge. This is especially important when new themes and ideas arrive, and the organization assimilates them. This has helped to internationalize MBE to grow into new market segments successfully. They have been able to do that by taking the 
information all the way to the top management and relying on effective decisionmaking on solution preferences. This includes prioritization and the timely allocation of budgets for potential exploitation of opportunities.

The importance of senior management in prioritizing is accepted across groups. For instance, a manager at the SME states that "senior management is influential in achieving success by leading the way when issues need to be addressed and prioritizing solutions. They see the information may be a possibility, and maybe in product development, they may see it as a must or something that will take resources, so then they tend to [for] some time [...] be quite critical to change." The role of trust in relationships is recognized and carries permanence if these relationships create exploitable opportunities. Relationship trust is a key aspect of opportunity recognition through sense-making and opportunity exploitation. A firm cannot have the ability to offer solutions on a consistent basis unless it develops flexible internal mechanisms. Organizational experiential learning strengthens the company's sensemaking capability to identify opportunities and reduce foreign market uncertainty. The uncertainty felt by the focal firm, but also by the customers, depends on the commitments signaled by the focal firm.

There are different levels of interactions in relationships, and therefore each relationship in an organization adds to collective learning based on the experiential knowledge. Learning is internalized from the bottom up, and the integration process should proceed similarly. However, sense-making-based decision-making is top-down. Our results shed light on how the study case firms individually learned through knowledge sharing with customers. Besides direct communications, the MBE has dropped the salesperson approach and treats its customers as partners or acts as their consultant. This method includes sensing an opportunity in the market and taking the idea to the client and discussing how they can jointly capitalize on it. This has yielded fruitful results for the company, as in autumn 2016 it signed an agreement for a joint venture project in the North American market.

The SME experienced that delivering on its reputation for offering customized solutions and customer care has led to growth in the international market. The SME had a major technical issue with generators it had supplied to one of the biggest wind turbine manufacturers in China. The client was upset with the situation. When it happened, the top management team along with technical staff immediately flew out to China and reached the site next day. The clients were so impressed that the top management had come there in person to sort out the problem that this changed the nature of the relationship. The SME had very fruitful discussions with its Chinese client and is now in a partnership with this big manufacturer. Although the client does not need to be partners with such a comparatively small firm, it had decided to take this step due to the care and sense of responsibility demonstrated by the SME. Other clients started contacting the SME directly for business, and the company now expects to generate more revenue from global sales than local. 


\subsection{Differences Between the Case Firms}

The MBE as a global leader in energy solution provider has a broader role in their relationships than the SME case, which may only be supplying parts, and this enables MBEs to have a better understanding of customer needs and knowledge of potential growth opportunities. The focus is turning to how they can ensure sustainable and efficient energy solutions in changing globally in general and urban environment in specific. With the evolving ecosystem, MBE management realized to stay ahead they need to be prepared; hence carrying out workshops and year-round training sessions for management and employees. This had a two-pronged effect, on the one hand, education related to external changes, and on the other internally, it helped management in finding a balance between conflicting demands for getting prospective proposals and or solution offerings approved. This lead to improved internal coordination as well as effectively sense-making of customer needs. The robust relationship knowledge development process influenced superior value provision for customers through advanced digital sustainable solutions by understanding customer operations of their assets/offering.

The SME case firm being a smaller organization with a thin top, with each one bringing in individual unique experience, expertise, and knowledge. They are continually exploring new ways, better solutions and quicker decision-making helped them in internationalization. They are working with customers requiring drivetrain technology, enabling them to produce effective but cost-efficient power generations through the optimized process and energy usage. Being ready to learn and patiently correct themselves, brought forth corrections in specific operational errors, change in processes and application of lessons learned in one relationship in other relationships (e.g., training customer staff to service products). They have been successful in bringing innovative solutions in marine and wind and energy storage through efficient and effective power generation solutions.

The MBE case firm developed efficient internal sharing conduits and had more extensive knowledge integration mechanisms in place compared to the SME. Therefore its knowledge acquisition is more efficient compared to the SME, and this can influence the extent of market expansion through the exploitation of potential opportunities. Due to its size, the SME has an edge in providing personalized service, making quick adjustments and revisions, and being more accessible. Despite the difference in size, there are similarities among the case firms; relationship knowledge development application has enabled them to convert identified opportunities into growth commitments internationally. Through close working with and paying attention to customers' lead to learning. Within this continuous interaction, trust nurtures, which is an essential prerequisite for sharing and collaborative efforts. The relationship building empowers the focal firm with network advantage. This is where MBE firm strongly benefited in service provision to customers on a long-term basis. The knowledge development influences strategy transformation ensuring solution offering according to customer requirement.

Both cases present quite similar commitment processes wherein they engage individuals at various levels in decision-making as well as implementation. This brings into play multiple change processes in parallel leading to a collective change. The 
awareness of the evolving ecosystem leads to a change in approaching the customer. Hence being able to differentiate themselves by the offering, the strengthening relationship results in a joint beneficial outcome. The interesting observation is that it seems that the dynamic capability rests with top management as a result of micromacro aggregation. The resulting change in relationship commitment builds on commitment towards the customer, his business that necessitates focal firm employees to be skilled to serve the customer. However, in the end, for MBE or MBEs to be their ultimate focus has to be on how well they can address customer needs through their offerings (present and/or future).

\section{Conclusions}

The two cases demonstrate that the processes of knowledge development, commitment decisions, and their implementation occur at the customer level. Socializing with the individual customer paves the way for experiential learning, which constitutes an input for more creative aspects of knowledge development. The cases also highlight the importance of trust-building. It is clear that trust-building is both a necessary input into the commitment processes and that the increased commitments increase the level of trust. The cases confirm that the processes of knowledge development and commitments occur at both ends of the relationship. This is an essential element of understanding why internationalization is an incremental process: Both parties have to pursue the processes. Internationalization, as we typically have understood this phenomenon, is an aggregation and accumulation of a series of processes at the mille-micro and micro levels. The same is true for the performance outcome, e.g., sales in a particular foreign market, which comprise the aggregation of many performance details, such as the jointly reached understanding of what a different agreement might imply to the business of the customer.

In this way, it becomes quite clear that the dynamic capability, the ability to internationalize, is to a large extent a dynamic capability to develop customer relationships. This is an important finding to understand for managers of MBEs or MBEs to be: it is far from only a matter of finding the best mode of operation in the foreign market, but also a matter of how to develop customer relationships.

It seems to us, that the study of the relationship knowledge development process confirms, tentatively, the assumptions on which the Uppsala model rests: the three sub-processes of learning, creating and trust-building all play an important role. Now this result should be more quantitatively confirmed in broader studies permitting generalization.

Our aim in this paper is to explore the influence of relationship knowledge development as a means of building dynamic capability in the internationalization process as envisioned in the Uppsala model (Vahlne and Johanson 2017). Our study performs a qualitative thematic analysis by comparing relationship learning in an MBE and an SME. Firstly, this study contributes by studying micro foundation level characteristics by focusing on individual learning in inter-firm relationships. This helps to understand how individual learning in interactions is a means to, understand customer needs and the purpose the offering is being consumed to satisfy. This 
learning concerns customer needs, their future needs, and awareness of the offering utilization pattern. The boundaries between products, services, and customer environments are blurring, with digitalization driving faster disruptions and customers desiring personalization and immediacy as the business landscape goes through continuous change.

The customer is one of the key conduits of learning in an organization's value chain. The organizational ability to design an offering based on relationship learning will open enormous growth opportunities to build new and strengthen existing business relationships. Companies use their consumer data to study and analyze changes in behavior and emerging trends. This provides insight into consumer preferences and identifies consumer groups in the existing consumer base that are to be targeted differently for a more productive relationship and the adoption of a strategy to attract non-consumer groups. In the Uppsala globalization model, the explanatory strength of dynamic capabilities has increased due to the inclusion of ambidexterity (Vahlne and Jonsson 2017). The impact from the dynamic capabilities can lead to the ability of the focal firm to over time, under changing needs and contexts, tap into operational capabilities that lead to excellent or satisfactory performance. The dynamic capabilities will result in changed commitments, quantitatively and/or qualitatively.

In the Uppsala model, the knowledge development process is the aggregate of three subprocesses: learning, creating and trust-building (Vahlne and Johanson 2017). Our findings show that organizations pursuing internationalization should focus on understanding customer needs wherein lay business opportunities. These possibilities arise from working closely with clients and offering need-based solutions, which in certain cases entails adding services to the product. With growing competition, eroding prices and commoditization, this provides new means for reaping higher value appropriation and creating differentiation via value-based solutions. Our results confirm that the extent to which customers share relevant information varies with the level of trust in a relationship. The study case organizations validate that strengthening knowledge development capabilities through skills and behavioral change is critical. It is important to be receptive to customer needs and sense-making concerning firm offerings. Few of our study organizations have ongoing strategic development programs in place to train and guide employees through the change process with the backing of top management. The involvement of customers fosters value creation not only through their sharing but also by involving their right individuals to contribute through their knowledge and expertise in the provider firm's processes.

To sum up, the commonalities and differences in knowledge development among the case companies, developing a personal relationship, paying attention to client communication and understanding their working are essential basics of ineffective knowledge sharing. It is critical to internalize acquired knowledge and evaluate it effectively; the sense-making process helps align customer needs with the organizational offering. The leadership role of management in prioritizing solutions paves the way for the smooth and efficient delivery of the offering to customers. The regular educational and technical training of employees enhances their ability to identify opportunities and market needs. The evolving market environment requires adding services to products as a growth strategy. The involvement of customers in solutions 
not only provides valuable input but also brings forth a closer working relationship and increased commitment. The creation of value through customized solutions can bring suppliers higher economic returns in the shape of value appropriation. It is postulated based on our results that these steps have helped the case organizations to exploit the identified opportunities through relationship learning profitably and to grow internationally.

We provide practical implications for managers; it is essential to develop open and well-defined communication conduits with customers. Efforts to provide a solution to address client needs must begin with understanding how the customers work, that is, their requirements and the job they intend to perform. Furthermore, our results confirm that a closer relationship can comfortably uncover needs that customers may not be aware of yet. Need identification enhances customer involvement in the value creation process, and collectively the supplier-customer can bring forth value-enhancing solutions. This awareness will help in developing a practical approach to managing inter-organizational conduits to achieve value appropriation objectives and grow in the market.

Obviously there are some limitations to what conclusions that can be drawn due to the methodological choices we have made. One is obvious. We have investigated two cases only and for these two companies only a couple of supplier-customer relationships. The results are in our opinion worthy of further investigation, but cannot at this stage be generalized. The character of the product and services traded within the relationship may affect the nature of it, for example, the density of knowledge exchange necessary. Then supplier-customer relationships are only one of the many sorts of relationships to various parties in the environment a company has to build and exploit. There may be differences due to the different content of the relationships. Many more studies are required before results can be generalized.

Still, we are strengthened in our belief that relationship knowledge development is a critical micro-foundation in the Uppsala model, deserving further research to certify the character of its influence.

Acknowledgements Open access funding provided by University of Vaasa (UVA).

Open Access This article is distributed under the terms of the Creative Commons Attribution 4.0 International License (http://creativecommons.org/licenses/by/4.0/), which permits unrestricted use, distribution, and reproduction in any medium, provided you give appropriate credit to the original author(s) and the source, provide a link to the Creative Commons license, and indicate if changes were made.

\section{References}

Abbott, A. (1988). The system of professions: An essay on the division of expert labor. Chicago: University of Chicago Press.

Andersson, E., \& Weitz, B. (1992). The use of pledges to build and sustain commitment in distribution channels. Journal of Marketing Research, 29(1), 18-34.

Aykol, B., \& Leonidou, L. C. (2018). Exporter-importer business relationships: Past empirical research and future directions. International Business Review, 27(5), 1007-1021. 
Cano-Kollmann, M., Cantwell, J., Hannigan, T. J., Mudambi, R., \& Song, J. (2016). Knowledge connectivity: An agenda for innovation research in international business. Journal of International Business Studies, 47(3), 255-262.

Chen, T. J. (2000). Network resources for internationalisation, the case of Taiwan's electronic firms. Taipei National Taiwan University (Mimeo).

Chesbrough, H. W. (2010). Business model innovation: Opportunities and barriers. Long Range Planning, 43(2-3), 354-363.

Coviello, N. E., Brodie, R. J., Danaher, P. J., \& Johnston, W. J. (2002). How firms relate to their markets: An empirical examination of contemporary marketing practices. Journal of Marketing, 66(1), 33-46.

Coviello, N., Kano, L., \& Liesch, P. W. (2017). Adopting the Uppsala model to a modern world: Macrocontext and microfoundations. Journal of International Business Studies, 48(9), 1151-1164.

Cunningham, M. T., \& Homse, E. (1986). Controlling the marketing-purchasing interphase: Resource development and organizational implications. Industrial Marketing and Purchasing, 1(2), 3-27.

Day, G. S. (2004). Which way should you grow. Harvard Business Review, 82(7-8), 24-25.

Drucker, P. F. (1999). Managing for results: Economic tasks and risk-taking decisions. Oxford: Butterworth-Heinemann.

Dunning, J. H., \& Lundan, S. M. (2008). Multinational enterprises and the global economy. Cheltenham: Edward Elgar.

Dyer, J. H., \& Singh, H. (1998). The relational view: Cooperative strategy and sources of interorganizational competitive advantage. Academy of Management Review, 23(4), 550-679.

Dyer, W. G., \& Wilkins, A. L. (1991). Better stories, not better constructs, to generate better theory: A rejoinder to Eisenhardt. The Academy of Management Review, 16(3), 613-619.

Edvardsson, B., Gustafsson, A., Kristensson, P., Magnusson, P., \& Matthing, J. (2006). Involving customers in new service development. London: Imperial College Press.

Eriksson, T. (2014). Processes, antecedents and outcomes of dynamic capabilities. Scandinavian Journal of Management, 30(1), 65-82.

Eriksson, K., Johanson, J., Majkgård, A., \& Sharma, D. D. (1997). Experiential knowledge and cost in the internationalization process. Journal of International Business Studies, 28(2), 337-360.

Eriksson, K., Majkgård, A., \& Sharma, D. D. (2000). Path dependence in the internationalization process. Management International Review, 40(4), 307-328.

Evers, N., \& Knight, J. (2008). Role of international trade shows in small firm internationalization: A network perspective. International Marketing Review, 25(5), 544-562.

Flick, U. (2014). An introduction to qualitative research (5th ed.). London: Sage Publications.

Forsgren, M. (2002). The concept of learning in the Uppsala internationalization process model: A critical review. International Business Review, 11(3), 257-277.

Ghauri, P. (2004). Designing and conducting case studies in international business research. In R. Marschan Piekkari \& C. Welch (Eds.), Handbook of qualitative research methods for international business (pp. 109-124). Cheltenham: Edward Elgar.

Guercini, S., \& Runfola, A. (2010). Business networks and retail internationalization: A case analysis in the fashion industry. Industrial Marketing Management, 39(6), 908-916.

Håkansson, H. (1982). International marketing and purchasing of industrial goods. London: Wiley.

Håkansson, H. (1989). Corporate technological behavior: Cooperation and networks. London: Routledge.

Håkansson, H., \& Johanson, J. (2001). Business network learning. Oxford: Elsevier Science Ltd.

Håkansson, L., \& Kappen, P. (2017). The 'Casino Model' of internationalization: An alternative Uppsala paradigm. Journal of International Business Studies, 48(9), 1103-1113.

Hart, S., \& Banbury, C. (1994). How strategy-making processes can make a difference. Strategic Management Journal, 15(4), 251-269.

Helfat, C. E., Finkelstein, S., Mitchell, W., Peteraf, M. A., Singh, H., \& Teece, D. J. (2007). Dynamic capabilities: Understanding strategic change in organizations. Malden: Blackwell Publishing.

Hohenthal, J. (2001). The creation of international business relationships: Experience and performance in the internationalization process. Department of Business Studies, Uppsala University

Jarvis, P. (2009). Learning to be a person in society: Learning to be me. In K. Illeris (Ed.), Contemporary theories of learning. London: Routledge.

Johanson, J., \& Vahlne, J.-E. (1977). The internationalization process of the firm-A model of knowledge development and increasing foreign market commitment. Journal of International Business Studies, 8(1), 23-32. 
Johanson, J., \& Vahlne, J.-E. (2003). Business relationship learning and commitment in the internationalization process. Journal of International Entrepreneurship, 1(1), 83-101.

Johanson, J., \& Vahlne, J.-E. (2006). Commitment and opportunity development in the internationalization process model. Management International Review, 46(2), 165-178.

Johanson, J., \& Vahlne, J.-E. (2009). The Uppsala internationalization process model revisited: From liability of foreignness to liability of outsidership. Journal of International Business Studies, 40(9), 1411-1431.

Johnson, J., Yin, E., \& Tsai, H. (2009). Persistence and learning: Success factors of Taiwanese firms in international markets. Journal of International Marketing, 17(3), 39-54.

Jonsson, A. (2007). Knowledge sharing across borders: A study in the IKEA world. Lund: Lund University Press.

Kindström, D., Kowalkowski, C., \& Sandberg, E. (2013). Enabling service innovation: A dynamic capabilities approach. Journal of Business Research, 66(8), 1063-1073.

Kirkup, M., \& Carrigan, M. (2000). Video surveillance research in retailing: Ethical issues. International Journal of Retail and Distribution Management, 28(11), 470-480.

Kohtamäki, M., Partanen, J., \& Möller, K. (2013). Industrial marketing management making a profit with $\mathrm{R}$ and $\mathrm{D}$ services-The critical role of relational capital. Industrial Marketing Management, 42(1), 71-81.

Langley, A. (2009). Studying processes in and around organizations. In D. A. Buchanan \& A. Bryman (Eds.), The Sage Handbook on Organizational Research Methods (pp. 409-429). London: Sage Publications.

Lehrer, M., Ordanini, A., De Fillippi, R., \& Miozzo, M. (2012). Challenging the orthodoxy of value co-creation theory: A contingent view of co-production in design-intensive business services. European Management Journal, 30(6), 499-509.

Loane, S., \& Bell, J. (2006). Rapid internationalisation among entrepreneurial firms in Australia, Canada, Ireland and New Zealand: An extension to the network approach. International Marketing Review, 23(5), 467-485.

Mainela, T., Puhakka, V., \& Servais, P. (2014). The concept of international opportunity in international entrepreneurship: A review and a research agenda. International Journal of Managagment Review, 16(1), 105-129.

Melin, L. (1992). Internationalization as a strategy process. Strategic Management Journal, 13(2), 99-118.

Miles, M. B., \& Huberman, A. M. (1994). Qualitative data analysis: An expanded sourcebook. Thousand Oaks: Sage Publications.

Morgan, R. M., \& Hunt, S. D. (1994). The commitment-trust theory of relationship marketing. Journal of Marketing, 58(3), 20-38.

Nonaka, I., \& Takeuchi, H. (1995). The knowledge-creating company. How Japanese companies create the dynamics of innovation. Oxford: Oxford University Press.

Pahlberg, C. (2001). Creation and diffusion of knowledge in subsidiary business networks. In H. Håkansson \& J. Johanson (Eds.), Business Network Learning (pp. 161-181). Oxford: Elsevier Science Ltd.

Santangelo, G. D., \& Meyer, K. E. (2017). Internationalization as an evolutionary process. Journal of International Business Studies, 48(9), 1114-1130.

Selnes, F., \& Sallis, J. (2003). Promoting relationship learning. Journal of Marketing, 67(3), 80-95.

Shane, S. (2000). Prior knowledge and the discovery of entrepreneurial opportunities. Organization Science, 11(4), 448-469.

Spender, J.-C. (1996). Making knowledge the basis of a dynamic theory of the firm. Strategic Management Journal, 17(SI), 45-62.

Teece, D. J. (2007). Explicating dynamic capabilities: The nature and micro-foundations of (sustainable) enterprise performance. Strategic Management Journal, 28(13), 1319-1350.

Teece, D. J. (2010). Business models, business strategy and innovation. Long Range Planning, 43(2-3), 172-194.

Teece, D. J. (2012). Dynamic capabilities: Routines versus entrepreneurial action. Journal of Management Studies, 49(8), 328-352.

Teece, D. J. (2014). A dynamic capabilities-based entrepreneurial theory of the multinational enterprise. Journal of International Business Studies, 45(1), 8-37.

Teece, D. J., Pisano, G., \& Shuen, A. (1997). Dynamic capabilities and strategic management. Strategic Management Journal, 18(7), 509-533. 
Töllner, A., Blut, M., \& Holzmüller, H. H. (2011). Customer solutions in the capital goods industry: Examining the impact of the buying center. Industrial Marketing Management, 40(5), 712-722.

Tuli, K. R., Kohli, A. K., \& Bharadwaj, S. G. (2007). Rethinking customer solutions: From product bundles to relational processes. Journal of Marketing, 71(3), 1-17.

Vahlne, J.-E., Ivarsson, I., \& Johanson, J. (2011). The tortuous road to globalization for Volvo's heavy truck business: Extending the scope of the Uppsala model. International Business Review, 20(1), $1-14$.

Vahlne, J.-E., \& Johanson, J. (2013). The Uppsala Model on evolution of the multinational business enterprise-From internalization to coordination of networks. International Marketing Review, 30(3), 189-210.

Vahlne, J.-E., \& Johanson, J. (2017). From internationalization processes 1977 to evolution 2017-The Uppsala model 40 years. Journal of International Business Studies, 48(9), 1087-1102.

Vahlne, J.-E., \& Jonsson, A. (2017). Ambidexterity as a dynamic capability in the globalization of the multinational business enterprise (MBE): Case studies of AB Volvo and IKEA. International Business Review, 26(1), 57-70.

Van de Ven, A. H., \& Huber, G. (1990). Longitudinal field research methods for studying processes of organizational change. Organization Science, 1(3), 213-219.

Winter, S. G., \& Szulanski, G. (2001). Replication as strategy. Organization Science, 12(6), 730-743.

Yin, R. K. (2003). Case study research: Design and methods (3rd ed.). Thousand Oaks: Sage Publications. 